\title{
Causes of bimodal stable isotope signatures in the feathers of a molt-migrant songbird
}

\author{
Eli S. Bridge, Adam M. Fudickar, Jeffrey F. Kelly, Andrea Contina, and \\ Sievert Rohwer
}

\begin{abstract}
Stable isotope ratios of hydrogen $(\delta \mathrm{D})$ and carbon $\left({ }^{13} \mathrm{C}\right)$ in feathers collected from Painted Buntings (Passerina ciris (L., 1758)) breeding in the midwestern United States revealed a surprising degree of variation in $\delta \mathrm{D}$, as well as a clear bimodal signal in $\delta^{13} \mathrm{C}$ in the innermost primary feather. Because this population does not molt on the breeding grounds, we reasoned that these observations could be due $(i)$ to birds migrating to two (or possibly more) distinct molting areas or (ii) to differences in the timing of molt (as opposed to molt location) relative to arrival at the stopover site. To evaluate these hypotheses, we collected feathers at a molting location in northwestern Mexico, which revealed patterns similar to those from the birds in the US (favoring the second hypothesis above). We suspect that some birds arrive at stopover sites and begin molting before their body tissues equilibrate to the new isoscape so that the first feathers grown represent a blend of materials from the breeding and stopover locations. Other birds may delay molt after arriving at the molting site, allowing them to equilibrate with the local isoscape and produce feathers with isotope signatures of the molting location.
\end{abstract}

Résumé : Les rapports d'isotopes stables d'hydrogène $(\delta \mathrm{D})$ et de carbone $\left(\delta^{13} \mathrm{C}\right)$ dans des plumes prélevées sur des passerins nonpareils (Passerina ciris (L., 1758)) se reproduisant dans le Midwest américain présentent un degré surprenant de variation de $\delta \mathrm{D}$, ainsi qu'un signal bimodal clair de $\delta^{13} \mathrm{C}$ dans les rémiges primaires les plus internes. Puisque cette population ne mue pas sur l'aire de reproduction, nous en déduisons que ces observations pourraient s'expliquer ( $i$ ) par le fait que les oiseaux migrent vers deux (et peut-être plus) aires distinctes de mue ou (ii) par des différences dans le calendrier de la mue (plutôt que dans le site de mue) par rapport à leur arrivée aux haltes migratoires. Afin d'évaluer ces hypothèses, nous avons récolté des plumes dans un site de mue dans le nord-ouest du Mexique qui présentent des patrons semblables à ceux des plumes des oiseaux des É.-U. (ce qui appuie l'hypothèse deuxième ci-haut). Nous soupçonnons que certains oiseaux arrivent à la halte migratoire et commencent leur mue avant que leurs tissus corporels n'aient établi un équilibre avec le nouvel isoscape, ce qui fait que les premières plumes à croître présentent un mélange de matériaux provenant du site de reproduction et de la halte migratoire. D'autres oiseaux pourraient retarder leur mue après leur arrivée au site de mue, ce qui leur permettrait d'atteindre un équilibre avec le nouvel isoscape et de produire des plumes portant les signatures du site de mue.

[Traduit par la Rédaction]

\section{Introduction}

Migratory songbirds demonstrate a wide variety of "strategies" for negotiating trade-offs between the costs and benefits of migratory movements. Although the advantages of migration for exploiting seasonal variation in primary productivity across latitudes are clear, the energetic requirements of long-distance flight along with the prospect of finding adequate refueling stops at unfamiliar locations cast migration as a somewhat dubious proposition (Alerstam and Lindström 1990). Moreover, migratory activity must be successfully incorporated into a species' overall life history in a manner that helps them secure resources and (or) territories while allow- ing time for other vital activities such as reproduction and feather molt.

One aspect of avian life histories that varies greatly among migratory species is the relative timing of molt and migration. Passerine birds typically do not attempt long-distance flights while replacing flight feathers, probably because of the aerodynamic costs of feather gaps (Hedenström 2003; Bowlin et al. 2009), and the high energetic demands of feather growth and sustained flight (Murphy 1996; Norberg 1996; Wikelski et al. 2003). Hence, molt and migration rarely occur simultaneously, and most North American songbirds carry out their most extensive feather molt on the breeding grounds just prior to migration (Howell et al.

Received 5 February 2011. Accepted 13 May 2011. Published at www.nrcresearchpress.com/cjz on 4 October 2011.

E.S. Bridge. University of Oklahoma, Center for Spatial Analysis, 101 David L Boren Boulevard, Norman, OK 73019, USA.

A.M. Fudickar* and A. Contina. University of Oklahoma, Department of Zoology, 111 East Chesapeake Street, Norman, OK 73019, USA.

J.F. Kelly. University of Oklahoma, Oklahoma Biological Survey and Department of Zoology, 111 East Chesapeake Street, Norman, OK 73019, USA.

S. Rohwer. Burke Museum and Department of Biology, University of Washington, Seattle, WA 98195, USA.

Corresponding author: Eli S. Bridge (email: ebridge@ou.edu).

*Present address: Max Planck Institute for Ornithology, Department of Migration and Immuno-ecology, Vogelwarte Radolfzell, Schlossallee 2, D-78315 Radolfzell, Germany. 
2010). However, many passerines that breed in the western United States molt their feathers at traditional molting sites between their breeding grounds and wintering areas (Young 1991; Rohwer et al. 2005, 2009b; Pyle et al. 2009). There is no evidence that these molt migrants grow the majority of their feathers while actively traveling-rather they appear to exploit highly productive molt-stopover locations where they can find sufficient food to fuel feather growth and prepare them for continued migration after acquiring new plumage (Leu and Thompson 2002; Rohwer et al. 2005). In a comparative context, the life histories of molt migrants offer interesting insights into how seasonal behaviors may be adapted to the regional landscape and how the spatial and temporal patterns of resource availability within that landscape may drive or maintain taxonomic diversification via differences in timing of molt and migration.

Among molt migrants, the Painted Bunting (Passerina ciris (L, 1758)) is a particularly interesting species because it occurs in two isolated, regional populations. The larger population breeds in the southern Midwest of the United States, whereas a much smaller eastern population breeds along the Atlantic coast (Fig. 1). The two populations are divided by a gap of more than $500 \mathrm{~km}$ throughout most of Alabama and they feature striking differences in their molt and migration schedules. Western birds begin fall migration in July and August and most individuals travel to temporary stopover sites in northwestern Mexico where they undergo a complete prebasic molt before moving farther south for the winter (Thompson 1991; Rohwer et al. 2009b). In contrast, the eastern population molts on the breeding grounds and delays migrating to wintering areas in southern Florida and the Caribbean until late September or October (Thompson 1991).

This divergence in eastern and western life histories motivated us to use stable isotope ratios of hydrogen and carbon to explore variability in migratory behavior among individual Painted Buntings from the western breeding population. Hydrogen and carbon isotopes in feathers are commonly used in studies of bird migration because they can link animals to geographic locations. Feathers are inert tissue, so they retain the isotopic signature of a bird in its molting location long after molt is complete. Hence, we can compare feather isotopes to large-scale geographic distributions of isotopes to infer molting locations (e.g.Hobson and Wassenaar 2008; Larson and Hobson 2009; Rohwer et al. 2011). The deuterium/hydrogen ratio $(\delta D)$ in rainwater decreases as one moves north across most of North America (Hobson and Wassenaar 2008), and is commonly used as an indicator of latitude. However, $\delta \mathrm{D}$ also varies with altitude, distance from the coast, and amount of precipitation (Bowen and Revenaugh 2003), which limits its utility as a latitudinal marker in areas like northern Mexico where the Sierra Madres, monsoonal rains, and the relatively narrow land mass separating the Atlantic and Pacific oceans introduce considerable isotopic variation (Hobson et al. 2009; Rohwer et al. 2009a). Carbon isotope ratios $\left({ }^{13} \mathrm{C} /{ }^{12} \mathrm{C}\right.$, or $\left.\delta^{13} \mathrm{C}\right)$ tell us whether animals derive their primary carbon source from plants that undergo $\mathrm{C}_{3}$ or $\mathrm{C}_{4}$ photosynthesis (Hobson and Wassenaar 2008). Although $\delta^{13} \mathrm{C}$ in feathers generally cannot pinpoint a molting location, it can differentiate between carbon sources acquired in different locations, e.g., arid grasslands dominated by $\mathrm{C}_{4}$ vegetation versus temperate for-
Fig. 1. Map of southern United States and Mexico showing breeding (light gray) and wintering (dark gray) distributions of Painted Buntings (Passerina ciris), as well as a hypothesized migration route for most Painted Buntings in the western population (large arrows), wherein birds fly to the Sonoran desert to molt during the monsoon season before moving on to the wintering grounds. Stars indicate the study locations in Oklahoma, USA, and Sinaloa, Mexico.

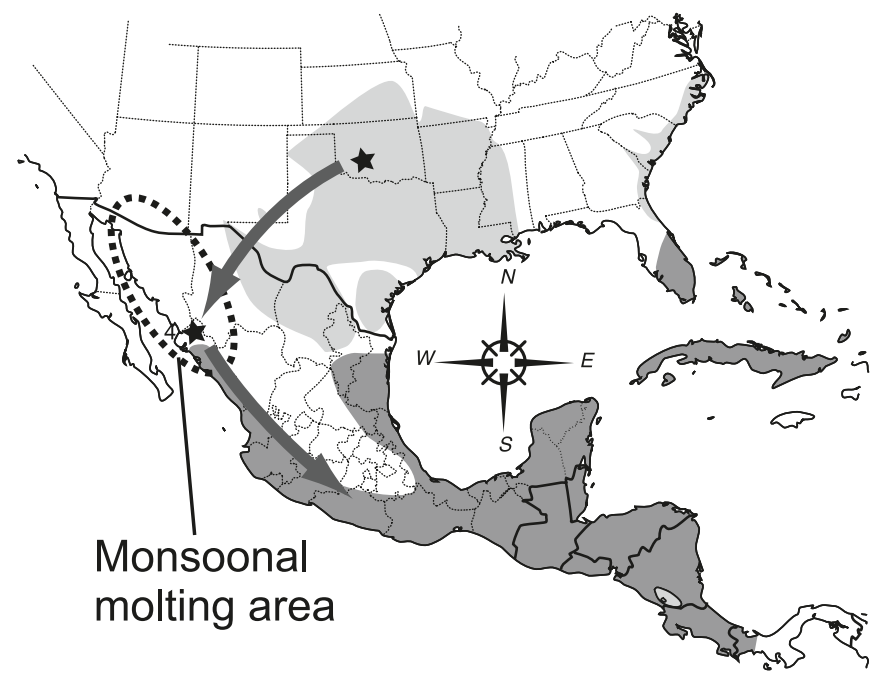

ests where $\mathrm{C}_{3}$ photosynthesis is more prevalent. Although stable isotopes have been used to study migration behavior in a number of species (see Hobson and Wassenaar 2008; Kelly et al. 2008), it has rarely been applied to molt migrants (i.e., birds that migrate to special molting locations; but see Fox et al. 2009 and Rohwer et al. 2009a).

Stable isotope signatures in feathers are generally thought to have a close correspondence to isotope ratios of the geographic area where feather molt occurs. But this inference presumes that birds grow their feathers after their body proteins have come into equilibrium with the local isoscape, which may not be the case in birds that molt shortly after migrating. Because feathers are synthesized from the prevailing supply of protein in the blood (Fox et al. 2009), they comprise proteins from both local, exogenous sources at the molting site and from endogenous sources. When molt rapidly follows migration, the isotopic signature of feathers grown early in the molting process should reflect the lag between the relatively rapid isotopic shift in exogenous sources of protein and the more gradual shift in isotope ratios from endogenous protein sources

An initial examination of stable isotope ratios of hydrogen and carbon in feathers from breeding Painted Buntings in southwestern Oklahoma (i.e., feathers grown in the previous calendar year) revealed evidence of notable shifts in dietary carbon between the first and the last primaries to be replaced, as well as a surprising degree of among-individual variation in $\delta \mathrm{D}$ and a clearly bimodal distribution of $\delta^{13} \mathrm{C}$ in the innermost primaries (Figs. 2a-2d). We reasoned that these findings could be attributed to either (1) different cohorts of birds flying to two markedly different locations to carry out molt or (2) differential deposition of stored nutrients (as opposed to dietary inputs) in growing feathers early in the molting period. A third explanation might be that some birds perform a partial molt on the breeding grounds (or nearby), 
pause feather replacement to migrate to the molting grounds, and then continue molting. However, molting Painted Buntings are virtually unknown in and around our study site in Oklahoma, and the locality data for molting Painted Buntings in museum collections strongly suggests that molt usually does not occur in breeding areas (Thompson 1991). Furthermore, actively molting Painted Buntings are extremely abundant in the coastal lowlands of northwestern Mexico, far south and west of the midwestern portion of their breeding range in the USA (Rohwer et al. 2009b), which indicates that a substantial portion of the western population molts in Mexico as opposed to breeding sites.

To evaluate our two hypotheses, we collected feathers from molting Painted Buntings in Sinaloa, Mexico, to determine whether birds sampled from a single molting site would demonstrate isotopic shifts and among-individual variation comparable with birds breeding in Oklahoma,USA. If the bimodal isotope data from Oklahoma are due to differences in the timing of molt and migration relative to isotopic turnover in the birds, then we should see a similar bimodal pattern among the birds from Sinaloa. However, a unimodal distribution among the Sinaloa birds would support the premise that birds in our breeding population practice substantially different migration strategies.

\section{Materials and methods}

\section{Feather collection}

Primary feather collection in Oklahoma occurred from May to August in 2006 and 2007 at two proximal breeding sites (26 km apart) on the Fort Sill Army Base $\left(34^{\circ} \mathrm{N}\right.$, $98^{\circ} \mathrm{W}$ ) in a combination of riparian woodland and mixedgrass prairie. A total of 30 adult (after-second-year) males were sampled at these sites. In Sinaloa, feather collection occurred from 27 July to 17 August at four rural sites in northern Sinaloa. One site was located in the Ahome Municipality $\left(25^{\circ} 58^{\prime} \mathrm{N}, 108^{\circ} 59^{\prime} \mathrm{W}\right)$ and the others in the El Fuerte Municipality (near $26^{\circ} 18^{\prime} \mathrm{N}, 108^{\circ} 48^{\prime} \mathrm{W}$ ). Painted Buntings begin arriving in Sinaloa in late July and most individuals examined evinced a full prebasic molt in this location. The birds congregate in grass-dominated agricultural fields and are sometimes highly aggressive (but not territorial) immediately before molt. For this study, we sampled 19 males and 19 females in Sinaloa; 29 were replacing primaries and the remainder were presumably about to begin molting. Three of the males were in their second year (i.e., they had green first-basic plumage), which is notable because second-year birds often do not replace some of their inner primaries during the second prebasic molt (Pyle 1997). However, secondyear males used in our analyses were actively growing inner primaries. More importantly, some females were likely also second-year birds, but we were unable to age them.

To assess changes in stable isotope deposition in feathers over the course of molt, we plucked both the innermost primary feather (P1), which is the first feather to be replaced during molt, and the outermost primary ( $\mathrm{P} 9$, the last to be replaced) from the majority of the birds sampled. In a few cases, P1 had recently been shed and was unavailable, but we still collected P9 and used it to examine isotope distributions. P9 was not newly replaced in any of the Sinaloa birds and was thus a year older than P1 in most birds. Accounting for feathers that were absent owing to molt or because samples were lost, sample sizes from Sinaloa were 34 for P1 and 37 for P9, and there were 33 birds from which we had isotope data for both $\mathrm{P} 1$ and P9. For 18 of these birds that were actively growing intermediate primaries (P3-P5), we also collected P3 or P4. Oklahoma birds were banded and released, whereas Sinaloa birds were prepared as museum specimens and archived at the University of Washington Burke Museum or the Universidad Nacional Autónoma de México Museo de Zoología.

\section{Stable isotope analysis}

We performed stable isotope analyses of the deuterium/ hydrogen ratio $(\delta \mathrm{D})$ and the ${ }^{13} \mathrm{C} /{ }^{12} \mathrm{C}$ ratio $\left(\delta^{13} \mathrm{C}\right)$. All stable isotope ratios are expressed in standard $\delta$ notation, where $\delta \mathrm{D}$ or $\delta^{13} \mathrm{C}=\left[\left(\right.\right.$ isotope ratio $_{\text {sample }} /$ isotope ratio standard $\left.)-1\right] \times 1000$. Consequently, $\delta \mathrm{D}$ and $\delta^{13} \mathrm{C}$ are expressed in parts per thousand $(\% \circ)$ deviation from a standard, which was Vienna Standard Mean Ocean Water for $\delta \mathrm{D}$ and Pee Dee Belemnite for $\delta^{13} \mathrm{C}$. All feathers were first cleaned with dilute detergent and then a 2:1 chloroform:methanol solution following Paritte and Kelly (2009). For hydrogen analyses, we packed a 140 $160 \mu \mathrm{g}$ piece of the distal vane of each feather into a $3.5 \mathrm{~mm} \times 5 \mathrm{~mm}$ silver capsule for insertion into an autosampling tray. For carbon analysis, we packaged separately a $350 \mu \mathrm{g}$ piece of feather into a tin capsule. Isotope ratio measurements were performed at the University of Oklahoma with a ThermoFinnigan Delta $\mathrm{V}$ isotope ratio mass spectrometer connected to an elemental analyzer (hydrogen analyses: TC/ EA, Thermo-Finnigan, Bremen, Germany; carbon analyses: CosTech elemental analyzer). Hydrogen stable isotope ratios were normalized according to Wassenaar and Hobson (2003) and are reported as the nonexchangeable fraction of feather hydrogen. For further details, see Kelly et al. (2009) and Paritte and Kelly (2009).

\section{Data analysis}

To address variation in molt and migration strategies among individuals, we examined variation among the individuals sampled at each locality for P1 and P9 separately. To assess shifts in carbon and hydrogen sources that occurred immediately prior to molt, we examined the difference between P1 and P9 in isotope ratios, expressed as P1 - P9. For groups of birds with little variation in their molt migration schedules and molting locations, we expect to see a roughly normal distribution of stable isotope ratios in their feathers. Therefore, we performed Shapiro-Wilk tests to determine whether distributions of isotope ratios departed from normality. We also calculated coefficients of bimodality for each distribution as a means of evaluating the extent to which the data departed from normality. The coefficient of bimodality was calculated according to SAS Institute Inc. (2004) so that values greater than 0.55 generally indicate a bimodal or multimodal distribution.

Differences in isotope ratios from P1 and P9 were derived by simply subtracting the P9 value from the P1 value. Because molt begins with $\mathrm{P} 1$ and ends with $\mathrm{P} 9$, a positive value for $\mathrm{P} 1-\mathrm{P} 9$ with respect to $\delta \mathrm{D}$ indicates that $\mathrm{P} 1$ was enriched in $\delta \mathrm{D}$ relative to $\mathrm{P} 9$ and that the bird moved from a relatively enriched environment to a more depleted area at some point during or before molt. Similarly, a positive value for P1 - P9 
for carbon analyses indicates a shift toward a diet dominated by $\mathrm{C}_{3}$ vegetation, whereas a negative value would indicate a dietary shift toward more $\mathrm{C}_{4}$ vegetation. Differences in mean isotopic shifts between the Oklahoma and the Sinaloa samples were tested using ANOVA, and we also used linear regressions to examine associations between shifts in $\delta \mathrm{D}$ and $\delta^{13} \mathrm{C}$ within individuals, which are evident in the isotopic signatures in P1 and P9. We tested for sex-based differences in isotope ratios among the Sinaloa birds (all birds from Oklahoma were males) using one-way ANOVA. All analyses were carried out in R (R Development Core Team 2004).

Because we lack detailed connectivity maps with regard to the migration routes of Painted Buntings, we have no way of knowing whether the birds captured in Oklahoma and Sinaloa are from the same general breeding population. Hence, we analyzed the data from these two sampling sites separately. Furthermore, because the feathers from the two populations were collected in different years, we cannot necessarily interpret subtle differences in feather isotopes between the sampling locations as evidence that we sampled two distinct populations.

\section{Results}

Among the feather samples from Oklahoma, we observed a marked departure from a normal distribution with regard to $\delta^{13} \mathrm{C}$ in P1 (Shapiro-Wilk: $p<0.001$ ). Both the coefficient of bimodalty (0.84) and visual inspection of the data (Fig. 2a) indicate a bimodal distribution in which about $60 \%$ of the feathers are consistent with $\mathrm{C}_{3}$ carbon sources and the remaining $40 \%$ consistent with $\mathrm{C}_{4}$ carbon sources. Interestingly, there was no such bimodal distribution with respect to P9 from the same birds. The distribution was skewed toward C4 carbon sources, which accounts for a marginally significant Shapiro-Wilk test $(p=0.06)$, but visual inspection and the coefficient of bimodality (0.53) suggest that the data from P9 are not bimodal in a manner similar to the P1 data (Fig. 2b).

There were also surprising aspects of the variation in $\delta \mathrm{D}$ among the feathers from Oklahoma. The distribution of $\delta \mathrm{D}$ in P1s from Oklahoma did not fail a test of normality (Shapiro-Wilk: $p=0.14$ ). However, the coefficient of bimodality was high (0.57), and the data are arguably bimodal in appearance with peaks at about $-45 \%$ and $-75 \%$ (Fig. $2 c$ ). The distribution of $\delta \mathrm{D}$ in $\mathrm{P} 9 \mathrm{~s}$ from Oklahoma was neither non-normal (Shapiro-Wilk: $p=0.76$ ) nor bimodal (coefficient of bimodality $=0.42$ ). However, the distribution was extremely broad, with values ranging from $-95 \%$ to $-26 \%$ o (Fig. 2d), which in some parts of North America would be the equivalent of over $10^{\circ}$ of latitudinal variation (see http:// waterisotopes.org, accessed 15 February 2011).

Isotope concentrations in the Sinaloa feathers were comparable with those of the Oklahoma feathers, but with a few important differences. Most notable perhaps is that the P1 feathers from the birds in Sinaloa had a bimodal distribution for $\delta^{13} \mathrm{C}$ that was very similar to what we observed in the birds from Oklahoma (Shapiro-Wilk: $p=0.02$; coefficient of bimodality $=0.62$; Fig. $2 a$ ). Also, as with the Oklahoma birds, $\delta^{13} \mathrm{C}$ in P9 was skewed toward $\mathrm{C} 4$ carbon sources, with a significant Shapiro-Wilk test $(p=0.006)$ and a marginally high coefficient of bimodality (0.54). Again from visual in-
Fig. 2. Histograms showing distributions of stable isotope ratios in first and ninth primary feathers of Painted Buntings (Passerina ciris) from Oklahoma, USA, (solid bars) and Sinaloa, Mexico (open bars).
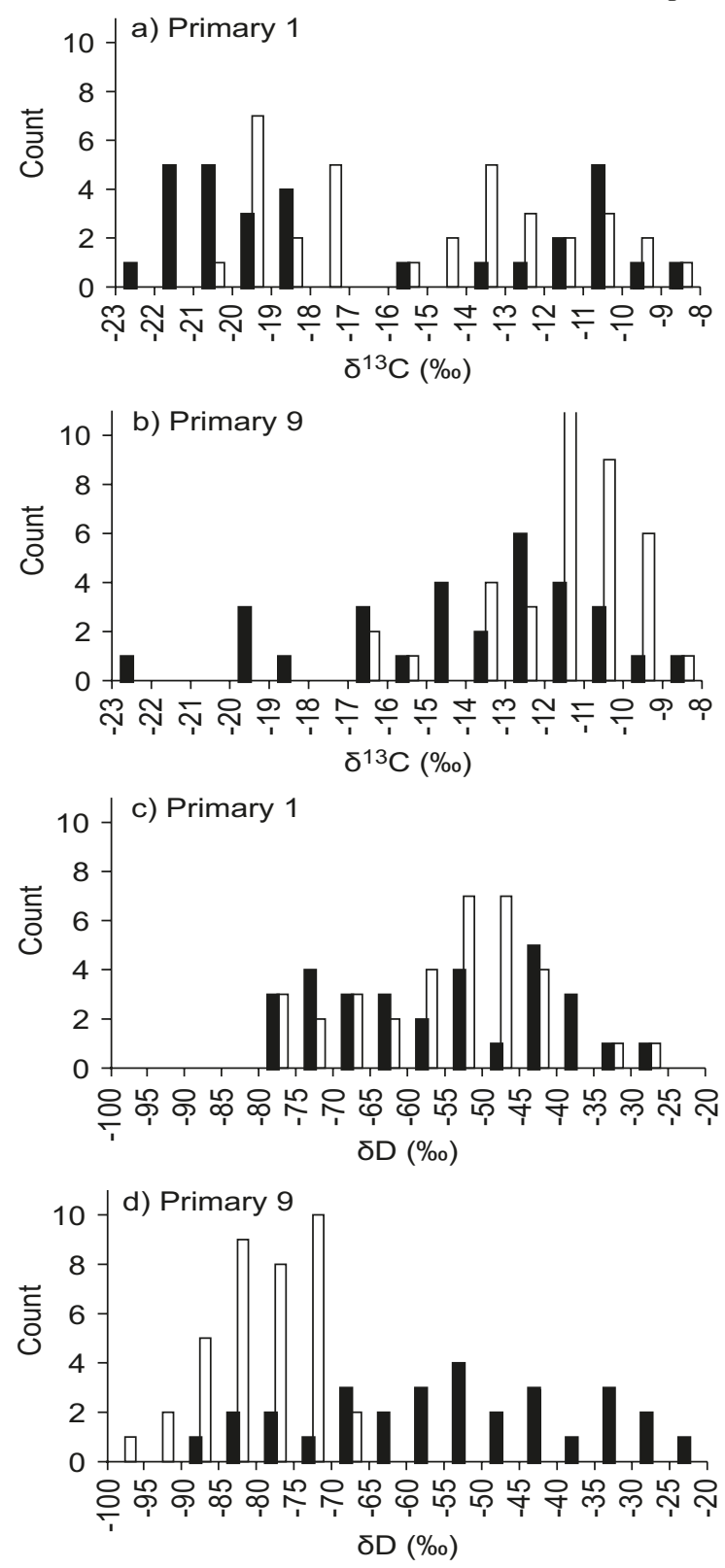

spection of the distribution, it is clear that the bimodality present with respect to $\mathrm{P} 1$ is not present in the distribution of $\delta^{13} \mathrm{C}$ in P9 (Fig. $2 b$ ). The bimodal distribution of $\delta^{13} \mathrm{C}$ values was not due to differences among the sexes, as C3 and $\mathrm{C} 4$ carbon signatures were present in both males and females. Females had a slightly lower $\delta^{13} \mathrm{C}$ value in $\mathrm{P} 1$ than males $(-18.34 \%$ $\pm 3.28 \%$ ov. $-16.04 \%$ $\pm 3.79 \%$ o $)$, but the difference was only marginally significant $\left(F_{[1,32]}=3.44, p=\right.$ 0.07). There was no sex-based difference with respect to $\mathrm{P} 9$ $\left(F_{[1,35]}=0.36, P=0.55\right)$.

$\delta \mathrm{D}$ values in $\mathrm{P} 1$ for the Sinaloa samples were also similar to those of the Oklahoma birds, but with a slightly narrower distribution and little indication of bimodality (Shapiro-Wilk: $p=0.25$; coefficient of bimodality $=0.41$; Fig. $2 c$ ). However, the distribution of $\delta \mathrm{D}$ in $\mathrm{P} 9$ was much narrower in the 
Sinaloa birds compared with those from Oklahoma (ShapiroWilk: $p=0.59$; coefficient of bimodality $=0.44$ ). This distribution largely conforms to our expectations of a sample collected from a single population, with limited variability and a normal distribution; it contrasts markedly with the corresponding data from Oklahoma, which had a flat, almost uniform distribution across a wider range of values (Fig. 2d). We found no sex-based differences in $\delta \mathrm{D}$ in either P1 $\left(F_{[1,36]}=0.28, p=0.60\right)$ or $\mathrm{P} 9\left(F_{[1,39]}=0.10, p=0.75\right)$ among the feathers from Sinaloa.

Within-individual differences in P1 and P9 revealed isotopic shifts during molt in many of the birds sampled. Among the birds from Oklahoma, $\delta^{13} \mathrm{C}$ increased (became less negative and more enriched) from P1 to P9 by $3.7 \%$ (one-sample Student's $t$ test: $t_{[29]}=-4.1, p<0.001$ ), which indicates a shift in the isotope ratio of the diet toward more $\mathrm{C}_{4}$ carbon sources. Similarly, the Oklahoma birds showed a small but significant increase in $\delta \mathrm{D}$ from P1 to P9 (mean $=$ 5.8\%; one-sample Student's $t$ test: $t_{[29]}=-2.2, p=0.03$ ). For P1 - P9 in $\delta^{13} \mathrm{C}$, the coefficient of bimodality was low $(0.45)$; for $\delta \mathrm{D}$, the coefficient was marginal $(0.55)$. ShapiroWilk tests on these distributions failed to show a significant departure from normality $\left({ }^{13} \mathrm{C}: p=0.22 ; \delta \mathrm{D}: p=0.16\right)$.

The isotopic shifts during molt were more dramatic in the Sinaloa birds. For $\delta^{13} \mathrm{C}$, there was a mean increase or enrichment (shift toward $\mathrm{C}_{4}$ carbon sources) of $4.4 \%$ from P1 to P9 (one-sample Student's $t$ test: $t_{[32]}=-5.84, p<0.001$; Figs. $2 a, 2 b)$ and for $\delta \mathrm{D}$ there was a mean decrease of $24.0 \%$ o (one-sample Student's $t$ test: $t_{[32]}=9.43, p<0.001$; see Figs. $2 c, 2 d$ ). We saw no evidence of bimodality with respect to the change in $\delta^{13} \mathrm{C}$ from P1 to P9 (coefficient of bimodality $=0.43$; Shapiro-Wilk: $p=0.36$ ) or to the change in $\delta \mathrm{D}$ (coefficient of bimodality $=0.38$; Shapiro-Wilk: $p=$ $0.55)$. Although males and females both underwent a shift toward $\mathrm{C}_{4}$ carbon sources, the difference between P1 and P9 was more pronounced in females, whose ${ }^{13} \mathrm{C}$ values increased by $6.50 \%$, on average, compared with an increase of $2.64 \%$ in males $\left(F_{[1,31]}=7.98, p=0.01\right)$. There was no such sex-based difference with regard to $\delta \mathrm{D}\left(F_{[1,31]}=0.40\right.$, $p=0.53$ ).

If we compare the change in $\delta^{13} \mathrm{C}$ to that of $\delta \mathrm{D}$ during the course of feather molt, we see a clear relationship between the two isotopic shifts in the Sinaloa birds. Enrichment in ${ }^{13} \mathrm{C}$ (a shift toward a $\mathrm{C}_{4}$ diet) is associated with depletion of deuterium (which typically indicates a northward shift in latitude or an upward shift in altitude), giving rise to a linear relationship $\left(F_{[1,31]}=10.37\right.$, adjusted $R^{2}=0.23, p=0.003$; Fig. 3). The association between within-individual changes in isotope signatures indicates a consistent pattern of change during molt for the two isotopes examined. There was no such relationship among the Oklahoma birds $\left(F_{[1,28]}=1.0\right.$, adjusted $R^{2}<0.01, p=0.32$ ).

Finally, from the 18 birds in Sinaloa from which we collected the third or fourth primary in addition to P1 and P9, it is apparent that the shift in feather isotope signatures occurs at different times with respect to molt progression for the carbon and hydrogen isotopes. Comparing the mean values from P1 and the intermediate feathers (either P3 or P4), ${ }^{13} \mathrm{C}$ increases from $-17.8 \% 0 \pm 1.6 \%$ (mean $\pm 95 \%$ confidence interval $(\mathrm{CI})$ ) to $-14.4 \%$ $\pm 1.4 \%$, whereas the difference between the intermediate feathers and $\mathrm{P} 9$, which
Fig. 3. The change in $\delta \mathrm{D}$ versus the change in $\delta^{13} \mathrm{C}$ in primary feathers over the course of molt for Painted Buntings (Passerina ciris) captured in Oklahoma, USA, (-) and Sinaloa, Mexico (O). The line is a linear regression fit to the Sinaloa data only (adjusted $R^{2}=0.23, p=0.003$ ).

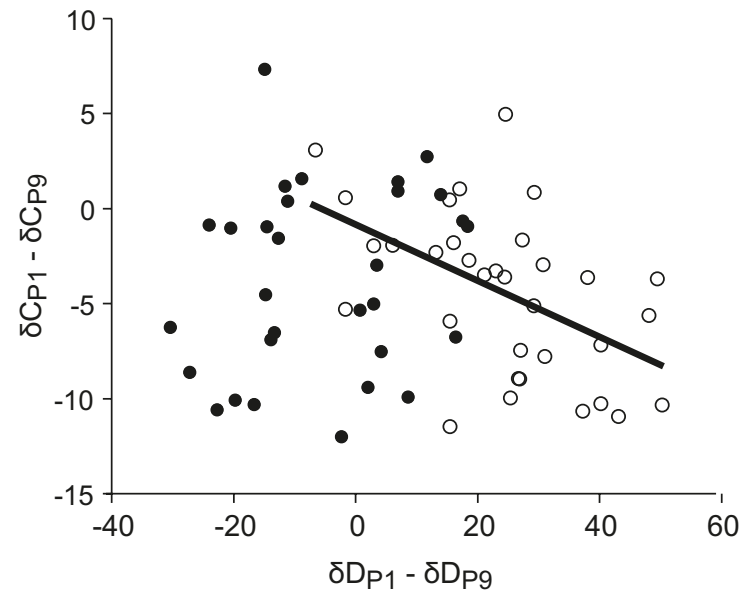

averaged $-12.8 \% \circ \pm 0.9 \%$, was somewhat less. Hence, the isotopic shift from $\mathrm{C}_{3}$ to $\mathrm{C}_{4}$ carbon was nearly complete when birds were molting P3 and P4 (Fig. 4a). Conversely, $\delta \mathrm{D}$ did not differ at all between P1 (mean $\pm 95 \% \mathrm{CI}=$ $-55.7 \% \circ \pm 4.5 \% \circ$ ) and the intermediate feathers (mean \pm $95 \% \mathrm{CI}=-56.0 \% 0 \pm 5.2 \%$ ) , but $\mathrm{P} 9$ had a value of $-81.5 \%$ o $\pm 4.1 \%$. Thus, the shift in $\delta \mathrm{D}$ occurred after the intermediate feathers began growing (Fig. $4 b$ ). These patterns were similar for males and females, although the intermediate primaries for males had more transitional $\delta^{13} \mathrm{C}$ values than for females (Figs. $4 a, 4 b$ ).

\section{Discussion}

Stable isotope signatures in feathers are determined primarily by a bird's diet around the time of molt and isotope ratios in the diet are heavily influenced by location (Hobson and Wassenaar 2008). Hence, the bimodal nature $\delta^{13} \mathrm{C}$ in P1 in the birds from Oklahoma was, at first, suggestive of a dramatic difference in migration route (i.e., molting location) or diet among two subsets of the population. However, finding a similar bimodal $\delta^{13} \mathrm{C}$ distribution in $\mathrm{P} 1$ from the molting birds in Sinaloa indicates that the degree of variation apparent in the Oklahoma samples need not be associated with different molting locations. Rather, the relative timing of migration and feather molt is perhaps the simplest explanation for our observations. More specifically, birds that arrive late to the molting area may begin replacing feathers immediately so that the first few feathers they grow bear the isotopic signature of the $\mathrm{C}_{3}$ photosynthetic environment that they just left. In this situation, there has not been sufficient time for their body tissues and protein reserves to assume isotope ratios that reflect their current environment, and it is not until molt has progressed to the more distal primaries that feather isotope ratios become similar to environmental isotope ratios. Conversely, birds that arrive relatively early to the molting area may wait for some time before beginning molt (perhaps more than 2 weeks for the earliest birds to arrive). Having had more time for body tissues to assume the isotopic signature of the molting area, the first feathers replaced by these 
Fig. 4. Mean isotope ratios for 8 female (๑) and 10 male ( $\square$ ) Painted Buntings (Passerina ciris) from Sinaloa, Mexico. For each bird, we analyzed P1, P9, and either P3 or P4 (P3 and P4 values were pooled). Error bars show $95 \%$ confidence intervals (CIs) around each mean.
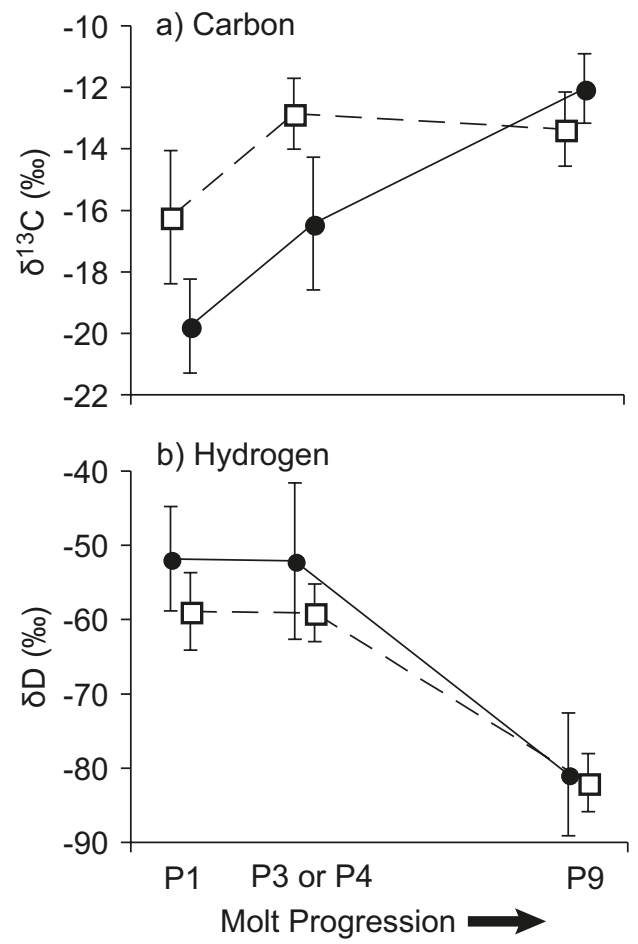

birds would indicate a $\mathrm{C}_{4}$ photosynthetic environment and would likely be very similar to the last feathers that they replace (see Fig. 5). The degree of mismatch or similarity between P1 and P9 (the first and last feathers molted) would likely apply to both $\delta^{13} \mathrm{C}$ and $\delta \mathrm{D}$, which would account for the correlation between the change in $\delta^{13} \mathrm{C}$ and in $\delta \mathrm{D}$ over the course of feather molt (Fig. 3).

It is a fair question to ask whether estimates of isotopic turnover rates and molt duration are in agreement with this explanation. Although empirical data for isotope turnover rates in Painted Buntings is lacking, It seems reasonable to assume that they would be similar to those of other small songbirds. Based on data from House Sparrows (Passer domesticus (L., 1758)), we might expect an isotope equilibration period of 15-40 days following a diet switch, depending on the particular tissue in question (Wolf et al. 2009). As for molt duration, detailed studies by Thompson (1991) indicate that individual Painted Buntings complete molt over the course of 40-50 days. Both of these time estimates align with the turnover hypothesis outlined above. Isotopic turnover occurs slowly enough that we might expect some birds to begin molt before reaching equilibrium, but turnover is rapid enough that it is likely to be complete before the outer primaries are replaced.

Further evidence for the time-based explanation is found in 18 birds for which we collected intermediate feathers (P3 or $\mathrm{P} 4)$. On average, $\delta^{13} \mathrm{C}$ for the intermediate feathers were between those of P1 and P9, suggesting that many of these birds were transitioning between the isotope ratios of their past and current environments as they molted their middle
Fig. 5. Graphic illustration of how the relative timing of molt and migration may lead to different stable isotope signatures in the feathers of Painted Buntings (Passerina ciris). The curved line represents $\delta^{13} \mathrm{C}$ in the body tissues of birds in association with a $\mathrm{C}_{3}$ to $\mathrm{C}_{4}$ isotopic shift in the diet, which we presume occurs when the birds arrive at the molting grounds (time point 0 on the $x$ axis). If the bird initiates molt immediately upon arrival, (lightly shaded area on the left), the feathers are replaced concurrently with a dramatic isotopic shift in the body tissues of the bird, leading to different isotope signatures in P1 and P9. For birds that delay molt for several days after arriving at the molting grounds (darkly shaded area on the right), there is no isotopic shift during molt and all feathers have a $\mathrm{C}_{4}$ isotopic signal.

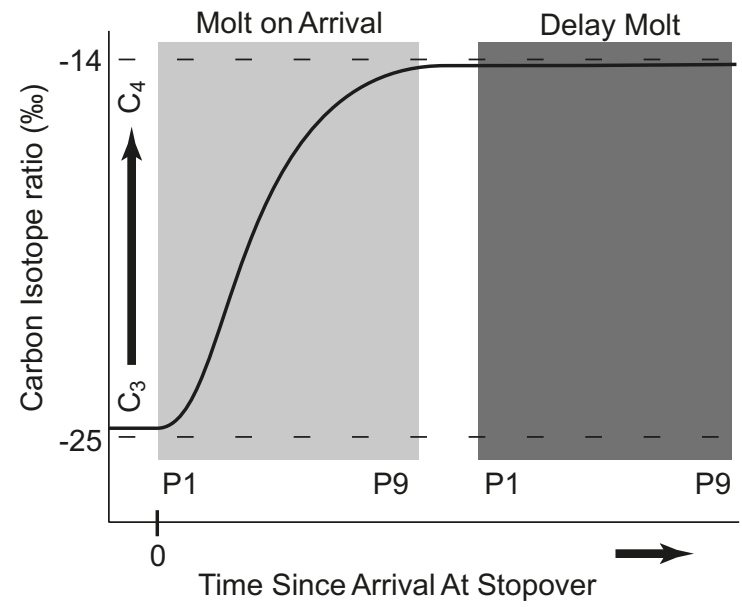

primaries. Interestingly, the intermediate feathers did not have such transitional values for $\delta \mathrm{D}$ and it appeared as though a shift toward more depleted feather tissue had yet to occur (Figs. $2 a-2 d$ ). The opposing patterns of turnover in $\delta \mathrm{D}$ and $\delta^{13} \mathrm{C}$ evident in Figs. $2 a-2 d$ are intriguing and numerous factors both environmental and physiological could account for them. One possible explanation is differences in how deuterium and ${ }^{13} \mathrm{C}$ are assimilated and incorporated into feathers. We note that given their affinity for xeric habitats, Painted Buntings probably have minimal water requirements and hydrogen turnover may be slowed because of low water intake and recycling of metabolic water during molt. Although there is a growing literature on isotope turnover rates (reviewed in Phillips and Eldridge 2006; Cerling et al. 2007; Martínez del Rio et al. 2009; Wolf et al. 2009; Oppel and Powell 2010), we know of no studies that concurrently investigate both carbon and hydrogen turnover rates. Environmental variation may also explain the discrepancy between carbon and hydrogen isotopes in the middle primaries. Whereas environmental carbon is likely to remain stable from year to year, hydrogen isotopes fluctuate greatly in a given area from year to year, and irrigation practices and runoff from high-elevation watersheds (both of which are likely to come into play in the Sinaloa field sites) can further complicate the picture.

As we mentioned previously, a partial molt on the breeding grounds followed by migration to the molting area and subsequent resumption of feather molt could give rise to some of the patterns that we have observed. However, there are several lines of evidence that suggest that the vast majority of the Painted Buntings that we studied molt all of their feathers on the molting grounds. First, as we stated earlier, 
actively molting Painted Buntings are rarely documented in the center of their western range (Thompson 1991). Second, from 2004 to 2010, we have captured over 300 Painted Buntings in and around study area in Oklahoma and none of them were molting (capture dates range from 20 May to 8 August). Third, birds captured early on the molting grounds tend to have uniformly worn primaries, indicating that molt has not yet started. Fourth, birds captured late on the molting grounds are often growing the last of their primaries, suggesting that most birds that initiate molt in Sinaloa complete it there. These observations do not entirely rule out the possibility of interrupted molts in some individuals. In fact, a small number of individuals captured in Sinaloa (3 out of 90 nonmolting birds) appeared to have molted some inner primaries and then suspended molt in a manner consistent with an interrupted molt (S. Rohwer, unpublished data). However, we believe that these individuals represent a nearly insignificant minority of the populations studied. In some situations, it is possible for an evaluation of $\delta D$ to link feather samples to general molting locations; however, an assignment test to determine if Oklahoma Painted Buntings molt on their breeding grounds is not feasible because of overlapping $\delta \mathrm{D}$ values in Oklahoma and northwestern Mexico. The degree of overlap is such that it is impossible to discriminate resident birds in northwestern Mexico from migrants with distributions in the southern United States (see our Fig. 1, as well as supplemental material in Rohwer et al. 2009a).

Although the relative timing of migration and molt appears to be the most parsimonious explanation for our findings, our data raise several other questions about variability in molt and migration behavior. Perhaps most notable is the extremely broad spread in $\delta \mathrm{D}$ in P9s from Oklahoma (Fig. $2 d$ ). In some regions of North America, this range of variation in $\delta \mathrm{D}$ would be the equivalent of over $10^{\circ}$ of latitudinal variation. It is possible that altitudinal variation in $\delta \mathrm{D}$ from precipitation could account for some of the $\delta \mathrm{D}$ variation in these feathers, but this scenario is unlikely because we have only found Painted Buntings molting at low elevations $(\sim 60 \mathrm{~m})$. Another possible explanation is that some molting Painted Buntings may use agricultural fields that are irrigated with water from a wide variety of sources. We note that predicted hydrogen isotope ratios in precipitation throughout most of the breeding range of western Painted Buntings differs little from those of Sinaloa (see http://waterisotopes.org, accessed 15 February 2011). Hence, the dramatic shift in $\delta D$ between P1 and P9 in the Sinaloa birds is probably due to depleted irrigation water or runoff derived from high-elevation (or more northerly) sources (Robertson 1991; Doucett et al. 2007). A broad distribution of isotope ratios among the innermost primaries can be explained by the fact that some birds begin replacing inner primaries before their body tissues have equilibrated to the local environment. However, Painted Buntings would not likely molt P9 until they had been on the molting grounds for more than 5 weeks (Rohwer et al. 2009b). So the tissue-equilibration explanation does not apply to the outer primaries. Comparing the P9s from Oklahoma with the corresponding sample from Sinaloa, it would appear that the birds from Oklahoma molt their outer primaries in a variety of isoscapes, and these individuals may not demonstrate site fidelity with regard to specific molting grounds, which appears to be typical for this species (Pyle et al. 2009).

We also have yet to firmly establish that some individuals molt immediately after arriving at molting sites, whereas others delay molt; we do not have an adaptive explanation for why they may do so. We have noted considerable variation in arrival times for Painted Buntings in Sinaloa and in their intensity of feather molt (i.e., how many feathers are grown simultaneously; Rohwer et al. 2009b; S. Rohwer, personal observation). Hence, a possible explanation for differences in molt initiation is the timing of migration, as well as of the cessation of reproduction. Birds whose nests fail late enough in the breeding season to preclude renesting may begin migration relatively early so that they arrive early on the molting grounds and subsequently delay molt for several days, perhaps to recover from the demands of migration, before assuming the energetic and nutritional burden of molt. Alternatively, birds that continue their reproductive efforts until late summer may migrate late so that they must begin molt immediately upon arrival at the molting grounds or risk falling behind in the annual schedule. Moreover, there is a period of intense aggression in Sinaloa that immediately precedes molt as birds compete (we presume) for productive grass fields (S. Rohwer, personal observation). Birds that arrive after a certain stage in this competition may simply skip this life-history stage and begin molting. Such a scenario might account for the bimodal nature of $\delta^{13} \mathrm{C}$ distributions among the innermost primaries.

We observed little evidence of differences between males and females. The slightly more dramatic isotopic shift in females compared with males may be related to females engaging in less territorial behavior at stopover. Or perhaps females are more likely to be late migrants from the breeding locations. There is also limited evidence that females in some breeding populations may initiate molt on the breeding grounds, then interrupt molt to migrate to the molting area where they subsequently resume molt (discussed above), although we have not observed molting females at our breeding site in Oklahoma. The more pronounced contrast in $\delta^{13} \mathrm{C}$ between P1 and P9 in females may be a result of interrupted molts, but a more intensive analysis of isotope ratios across all of the primaries is necessary to resolve this issue.

Much remains to be explored in this study system. We do not address the possibility that differences in diets on the breeding grounds could account for among-individual bimodality in P1. Differential preferences for certain food types or (more likely) differences in the types of food available on specific breeding territories could yield non-normal distributions in isotope ratios, especially with regard to $\delta^{13} \mathrm{C}$. The correspondence between $\delta \mathrm{D}$ and $\delta^{13} \mathrm{C}$ shifts in the Sinaloa birds (Fig. 3) argues against this diet-based explanation, as $\delta \mathrm{D}$ should be more or less uniform in a given area regardless of specific food sources. Except for the unlikely occurrence of a close, region-wide correspondence between $\delta \mathrm{D}$ and $\delta^{13} \mathrm{C}$ in diets of Painted Buntings across breeding habitats, we see no explanation for the relationship between $\delta \mathrm{D}$ and $\delta^{13} \mathrm{C}$ shifts other than isotope turnover time following migration. Nevertheless, we have no way of knowing where the birds from Sinaloa came from and it is possible that differences on the breeding grounds can contribute to differences in P1 isotope signatures. Perhaps a future evaluation of juvenile pri- 
mary feathers, which we know will correspond with food sources on the breeding grounds, will allow us to examine the possibility of dietary differences among birds in their breeding areas.

Stable isotopes can be a useful tool for studying migration (Langin et al. 2007), but it is important to interpret results with care, especially when certain basic information about the life history of a study organism is unknown or uncertain (Larson and Hobson 2009). Isotope ratios can provide valuable geographical and dietary information about animal populations and they have often been used to infer connectivity between the wintering and breeding grounds used by migratory bird populations. However, lag times associated with environmental equilibration of isotopes in body tissues must be considered in species that make rapid long-distance migratory movements. As we improve our understanding of these issues, we will greatly enhance our capacity to use stable isotopes to study animal movements. For example, we may be able to make inferences about stopover behavior and breeding activity based on samples taken at a single location (see Rohwer et al. 2009a; Oppel and Powell 2010). Such capabilities would be of great benefit as we seek to document changes in migration behavior in an era of rapid global change.

\section{Acknowledgements}

We thank C. Wood, R. Faucett, V. Rohwer, M. Ortiz, and J. Navarro for their help in collecting specimens in Mexico. Collecting for this project was approved by the Animal Care and Use Committees of both the University of Washington and the University of Oklahoma and was conducted under permits granted to the University of Washington Burke Museum to A. Navarro (Mexico) and J.F.K. (United States). We thank P. Bjornen and R. Maynard, who performed the majority of the isotope analyses. This work was funded by National Science Foundation (DEB: 0946685 and IOS: 0541740), by a grant from the US Fish and Wildlife Service, and by the Burke Museum Endowment for Ornithology. Logistical support came from the University of Washington Burke Museum, Universidad Nacional Autónoma de México Museo de Zoología, the Oklahoma Biological Survey, and the University of Oklahoma Department of Zoology.

\section{References}

Alerstam, T., and Lindström, A. 1990. Optimal bird migration: the relative importance of time, energy and safety. In Bird migration: physiology and ecophysiology. Edited by E. Gwinner. SpringerVerlag, Berlin. pp. 331-351.

Bowen, G.J., and Revenaugh, J. 2003. Interpolating the isotopic composition of modern meteoric precipitation. Water Resour. Res. 39(10): 1299-1311. doi:10.1029/2003WR002086.

Bowlin, M.S., Muijres, F., Johansson, C., Von Busse, R., and Hedenstrom, A. 2009. Aerodynamic costs of flying with holey wings. Comp. Biochem. Physiol. Part A Mol. Integr. Physiol. 153A(2, Suppl. 1): S122.

Cerling, T.E., Ayliffe, L.K., Dearing, M.D., Ehleringer, J.R., Passey, B.H., Podlesak, D.W., Torregrossa, A.-M., and West, A.G. 2007. Determining biological tissue turnover using stable isotopes: the reaction progress variable. Oecologia (Berl.), 151(2): 175-189. doi:10.1007/s00442-006-0571-4. PMID:17186277.

Doucett, R.R., Marks, J.C., Blinn, D.W., Caron, M., and Hungate,
B.A. 2007. Measuring terrestrial subsidies to aquatic food webs using stable isotopes of hydrogen. Ecology, 88(6): 1587-1592. doi:10.1890/06-1184. PMID:17601150.

Fox, A.D., Hobson, K.A., and Kahlert, J. 2009. Isotopic evidence for endogenous protein contributions to greylag goose Anser anser flight feathers. J. Avian Biol. 40(2): 108-112. doi:10.1111/j.1600048X.2009.04720.x.

Hedenström, A. 2003. Flying with holey wings. J. Avian Biol. 34(4): 324-327. doi:10.1111/j.0908-8857.2003.03324.x.

Hobson, K.A., and Wassenaar, L.I. 2008. Tracking animal migration with stable isotopes. Elsevier-Verlag, New York.

Hobson, K.A., Van Wilgenburg, S.L., Larson, K., and Wassenaar, L.I. 2009. A feather hydrogen isoscape for Mexico. J. Geochem. Explor. 102(2): 63-70. doi:10.1016/j.gexplo.2009.02.002.

Howell, S.N.G., Roger Tory Peterson Institute., and National Wildlife Federation. 2010. Molt in North American birds. Houghton Mifflin Harcourt, Boston.

Kelly, J.F., Johnson, M.J., Langridge, S., and Whitfield, M. 2008. Efficacy of stable isotope ratios in assigning endangered migrants to breeding and wintering sites. Ecol. Appl. 18(3): 568-576. doi:10.1890/07-0027.1. PMID:18488617.

Kelly, J.F., Bridge, E.S., Fudickar, A.M., and Wassenaar, L.I. 2009. A test of comparative equilibration for determining non-exchangeable stable hydrogen isotope values in complex organic materials. Rapid Commun. Mass Spectrom. 23(15): 2316-2320. doi:10. 1002/rcm.4150. PMID:19575406.

Langin, K.M., Reudink, M.W., Marra, P.P., Norris, D.R., Kyser, T.K., and Ratcliffe, L.M. 2007. Hydrogen isotopic variation in migratory bird tissues of known origin: implications for geographic assignment. Oecologia (Berl.), 152(3): 449-457. doi:10. 1007/s00442-007-0669-3. PMID:17370093.

Larson, K.W., and Hobson, K.A. 2009. Assignment to breeding and wintering grounds using stable isotopes: a comment on lessons learned by Rocque et al. J. Ornithol. 150(3): 709-712. doi:10. 1007/s10336-009-0408-0.

Leu, M., and Thompson, C.W. 2002. The potential importance of migratory stopover sites as flight feather molt staging areas: a review for neotropical migrants. Biol. Conserv. 106(1): 45-56. doi:10.1016/S0006-3207(01)00228-2.

Martínez del Rio, C., Wolf, N., Carleton, S.A., and Gannes, L.Z. 2009. Isotopic ecology ten years after a call for more laboratory experiments. Biol. Rev. Camb. Philos. Soc. 84(1): 91-111. doi:10. 1111/j.1469-185X.2008.00064.x. PMID:19046398.

Murphy, M.E. 1996. Energetics and nutrition of molt. In Avian energetics and nutritional ecology. Edited by C. Carey. Chapman and Hall, New York. pp. 158-198.

Norberg, U.M. 1996. Energetics of flight. In Avian energetics and nutritional ecology. Edited by C. Carey. Chapman and Hall, New York. pp. 199-249.

Oppel, S., and Powell, A.N. 2010. Carbon isotope turnover in blood as a measure of arrival time in migratory birds using isotopically distinct environments. J. Ornithol. 151(1): 123-131. doi:10.1007/ s10336-009-0434-y.

Paritte, J.M., and Kelly, J.F. 2009. Effect of cleaning regime on stable-isotope ratios of feathers in Japanese Quail (Coturnix japonica). Auk, 126(1): 165-174. doi:10.1525/auk.2009.07187.

Phillips, D.L., and Eldridge, P.M. 2006. Estimating the timing of diet shifts using stable isotopes. Oecologia (Berl.), 147(2): 195-203. doi:10.1007/s00442-005-0292-0. PMID:16341714.

Pyle, P. 1997. Identification guide to North American Birds. Part I. Columbidae to Ploceidae. Slate Creek Press, Bolinas, Calif.

Pyle, P., Leitner, W.A., Lozano-Angulo, L., Avilez-Teran, F., Swanson, H., Limón, E.G., and Chambers, M.K. 2009. Temporal, spatial, and annual variation in the occurrence of molt-migrant 
passerines in the Mexican monsoon region. Condor, 111(4): 583590. doi:10.1525/cond.2009.090085.

R Development Core Team. 2004. R: a language and environment for statistical computing. R Foundation for Statistical Computing, Vienna, Austria. Available from http://www.r-project.org/.

Robertson, F.N. 1991. Geochemistry of ground water in alluvial basins of Arizona and adjacent parts of Nevada, New Mexico, and California. US Geol. Surv. Professional Pap. No. 1406-C.

Rohwer, S., Butler, L.K., and Froehlich, D.R. 2005. Ecology and demography of east-west differences in molt scheduling in Neotropical migrant passerines. In Birds of two worlds. Edited by R. Greenberg and P.P. Marra. Johns Hopkins University Press, Baltimore, Md. pp. 87-105.

Rohwer, S., Hobson, K.A., and Rohwer, V.G. 2009a. Migratory double breeding in Neotropical migrant birds. Proc. Natl. Acad. Sci. U.S.A. 106(45): 19050-19055. doi:10.1073/pnas. 0908121106. PMID:19858484.

Rohwer, V.G., Rohwer, S., and Ramirez, M.F.O. 2009b. Molt biology of resident and migrant birds of the monsoon region of west Mexico. Ornitol. Neotrop. 20(4): 565-584.

Rohwer, S., Hobson, K., and Yang, S. 2011. Stable isotopes ( $\delta D$ ) reveal east-west differences in scheduling of molt and migration in
Northern Rough-winged Swallows (Stelgidopteryx serripennis). Auk 126(3): 522-530. doi:10.1525/auk.2011.10273.

SAS Institute Inc. 2004. SAS/STAT version 9.1: user's guide. SAS Institute Inc., Cary, N.C.

Thompson, C.W. 1991. The sequence of molts and plumages in Painted Buntings and implications for theories of delayed plumage maturation. Condor, 93(2): 209-235. doi:10.2307/1368938.

Wassenaar, L.I., and Hobson, K.A. 2003. Comparative equilibration and online technique for determination of non-exchangeable hydrogen of keratins for use in animal migration studies. Isotopes Environ. Health Stud. 39(3): 211-217. doi:10.1080/ 1025601031000096781. PMID:14521282.

Wikelski, M., Tarlow, E.M., Raim, A., Diehl, R.H., Larkin, R.P., and Visser, G.H. 2003. Costs of migration in free-flying songbirds. Nature (London), 423(6941): 704. doi:10.1038/423704a. PMID 12802324

Wolf, N., Carleton, S.A., and Martínez del Rio, C. 2009. Ten years of experimental animal isotopic ecology. Funct. Ecol. 23(1): 17-26. doi:10.1111/j.1365-2435.2009.01529.x.

Young, B.E. 1991. Annual molts and interruption of the fall migration for molting in Lazuli Buntings. Condor, 93(2): 236250. doi:10.2307/1368939. 